\title{
SALÁRIO DIFERIDO OU EMPRÉSTIMO COMPULSÓRIO
}

Deferred wage or compulsory loan

Área: Trabalho. Salário diferido.

\section{Luciana Carneiro da Rosa Aranalde ${ }^{1}$ \\ Mestre em Direito do Trabalho}

Marcel de Ávila Soares Marques ${ }^{2}$

Especialista em Direito e Processo do Trabalho

RESUMO: O presente trabalho tem como objetivo analisar os conceitos de salário, remuneração, décimo terceiro salário e adicional de um terço de férias e a possibilidade de parcelamento de tais rubricas a partir das alterações introduzidas pela Lei 13.467/17 (Reforma Trabalhista). Avaliarse-á, sob a nova perspectiva legal, as formas e a época de pagamento efetivo de tais parcelas além do projeto de lei em andamento no Congresso Nacional que viabiliza o pagamento parcelado dessas rubricas. Por último, tecer-se-á considerações sobre a nova regra inserida no texto da CLT, através do artigo 611-A que ao ampliar a autonomia da vontade das partes para dispor sobre o contrato de trabalho, estabeleceu a prevalência do negociado sobre o legislado.

PALAVRAS-CHAVE: Salário. Décimo Terceiro Salário. Terço de Férias. Parcelamento. Diferimento.

ABSTRACT: This paperaims to analyze the concepts of salary, remuneration, thirteenth salary and additional one-third vacation and the possibility of splitting up such items from the changes introduced by Law 13.467 / 17 (Labor Reform). It will be evaluated, under the new legal perspective, the forms and the time of effective payment of such installments, in addition to the bill in progress in the National Congress that makes possible the installment payment of these items. Finally, considerations will be made about the new rule inserted in the text of the CLT, through article 611-A which, by expanding the autonomy of the parties' will to dispose of the employment contract, established the prevalence of the negotiated over the legislated.

Professora e Advogada trabalhista.

2 Professor e Juiz do Trabalho. 
KEYWORDS: Salary. Thirteen first salary. Vacation Rosary. Installment.

SUMÁRIO: Introdução. 1. Salário e remuneração. 1.1 Décimo terceiro salário. 1.2 Férias e adicional de um terço. 2. Salário diferido ou empréstimo compulsório. 3. Possibilidade de parcelamento. Considerações finais. Referências bibliográficas.

\section{Introdução}

O vínculo empregatício é sustentado por alguns pilares, sendo que a legislação trabalhista traz expresso no artigo $2^{\circ}$, da CLT (Decreto Lei 5.452, de $1^{\circ}$ de maio de 1943), que é considerado empregador "a empresa, individual ou coletiva, que, assumindo os riscos da atividade econômica, admite, assalaria e dirige a prestação de serviço". Já o artigo $3^{\circ}$, do mesmo diploma legal, define que empregado "é toda a pessoa física que prestar serviço de natureza não eventual a empregador, sob dependência deste e mediante salário".

Como toda e qualquer relação, aquela existente entre empregados e empregadores é regida por deveres e obrigações. A principal obrigação por parte do empregado é fornecer e disponibilizar sua força e tempo de trabalho. Em contrapartida, as principais obrigações do empregador é remunerar, ou seja, pagar o salário pelo trabalho prestado, e disponibilizar trabalho.

Disponibilizar trabalho significa possibilitar a prestação de serviços, pois impossível caracterizar-se tal vínculo na hipótese de o empregador contratar um empregado para deixá-lo parado, sem trabalhar, situação já definida pelo conhecido jargão popular "deixar o empregado na geladeira", com o objetivo, por exemplo, de impedir o acesso de seus concorrentes à mão-de-obra daquele empregado específico. Tal situação não se confunde com o contrato de trabalho intermitente, onde o empregador contrata um empregado para que possa convocálo, conforme sua necessidade, autorizando o contratado a se manifestar alegando sua indisponibilidade.

Como visto, tanto no artigo legal que define a figura do empregador, quanto naquele que define a figura do empregado consta a figura do pagamento e consequente percepção do salário. A onerosidade, portanto, é requisito essencial para configuração do vínculo de emprego.

Inegável que a principal obrigação do empregador é pagar a remuneração. Sabe-se da existência dos trabalhos voluntários, que tem legislação específica, mas além de ser um número reduzido de situações não é o alvo deste estudo. 
O presente trabalho centrar-se-á na análise e debate do pagamento do salário, bem como no conceito e época de pagamento de dois institutos remuneratórios, quais sejam, décimo terceiro salário e adicional de um terço de férias. Debater-se-á a forma de pagamento e, principalmente, o momento do pagamento de cada uma dessas verbas.

Cumpre destacar que tais verbas figuram, frequentemente, no rol de pedidos das reclamatórias trabalhistas e constata-se, na maioria dos casos, o inadimplemento no decorrer do contrato de emprego, sendo esse um dos principais motivos que levam à judicialização quando do término da relação empregatícia.

O Conselho Nacional de Justiça relatou que, de janeiro a julho de 2019, as reclamatórias trabalhistas ajuizadas versavam 233.346 dos casos sobre décimo terceiro salário em 242.966 sobre as férias proporcionais, mostrando que são direitos habitualmente não satisfeitos regularmente pelos empregadores. ${ }^{3}$

Um dos objetivos do presente artigo é fomentar o debate quanto à possibilidade de garantir-se uma forma de pagamento mais efetiva de tais direitos, reduzindo o risco de seu inadimplemento, facilitando o cumprimento por parte do empregador e possibilitando um acesso mais constante e uniforme a esses valores pelos empregados.

\section{Salário e remuneração}

Maurício Godinho Delgado (2002, p. 645) define que "o contrato de trabalho é um contrato bilateral, sinalagmático e oneroso, por envolver um conjunto diferenciado de prestações e contraprestações recíprocas entre as partes, economicamente mensurável".

Através dessa definição, é possível constatar que a onerosidade é uma das principais caraterísticas do contrato de trabalho e não poderia ser diferente, pois a sua consequência (pagamento de salário) é que permite a inserção do trabalhador no moderno sistema econômico, garantindo a sua conexão ao processo produtivo.

O objeto do contrato de trabalho é o dispêndio de energia humana de um agente em prol de outro. Exatamente por esse motivo, o pagamento do salário se caracteriza como a principal obrigação do empregador na esfera do contrato de emprego, afinal não é possível devolver ao empregado a energia que dispendeu na consecução de certa atividade, além de ser inegável que a remuneração pelo

\footnotetext{
3 CONSELHO NACIONAL DE JUSTIÇA. Justiça em números 2019. Disponível em: < https:// www.cnj.jus.br/pesquisas-judiciarias/justica-em-numeros/>. Acesso em: 10 abr. 2020.
} 
serviço prestado também é responsável por "girar a roda" da economia, pois é através dela que o cidadão consegue ter acesso aos bens de consumo para a sua subsistência, fomentando, assim, o processo produtivo, a circulação de riqueza e a melhoria das condições sociais.

O artigo 457 da CLT (Decreto Lei 5.452, de $1^{\circ}$ de maio de 1943) conceitua salário como a contraprestação do serviço devida e paga diretamente pelo empregador ao empregado. Já o conceito de remuneração é mais amplo, nele inserido, além do salário, todos os demais valores recebidos, ainda que disponibilizados por terceiros, como, por exemplo, as gorjetas.

Destarte, os conceitos de remuneração e salário mais utilizados pela doutrina e pela jurisprudência é no sentido de que "a remuneração é o gênero das parcelas contraprestativas devidas e pagas ao empregado e salário é a espécie mais importante de tais parcelas, sendo esta paga diretamente pelo empregador" (BARROS, 2009, p.733).

A própria CLT (Decreto Lei 5.452, de $1^{\circ}$ de maio de 1943) faz tal distinção ao estabelecer, em seu artigo 457, que "compreende-se na remuneração do empregado, para todos os efeitos legais, além do salário devido e pago diretamente pelo empregador, como contraprestação do serviço, as gorjetas que receber". As gorjetas são valores dispensados por terceiros ao empregado e, mesmo não sendo pagas diretamente pelo empregador, não caracterizando, assim, espécie salário, integram o gênero remuneração.

Importante a distinção entre salário e remuneração, pois os institutos, que serão tratados neste trabalho, utilizam a remuneração como base de cálculo do chamado salário diferido, ou seja, tanto o décimo terceiro salário como o terço adicional de férias serão calculados com base na remuneração.

Maurício Godinho Delgado (2002, p. 695) doutrinou acerca da influência do salário no cálculo de demais verbas ao explicar o "efeito expansionista circular dos salários", que é a sua aptidão de produzir repercussões sobre outras parcelas trabalhistas e, até mesmo, de outra natureza, como ilustrativamente, a de cunho previdenciário.

Quanto ao pagamento efetivo do salário, o artigo 459 da CLT (Decreto Lei 5.452, de $1^{\circ}$ de maio de 1943), prevê que o seu pagamento, "qualquer que seja a modalidade do trabalho, não deve ser estipulado por período superior a um mês, salvo no que concerne a comissões, percentagens e gratificações". Tal previsão legal é complementada pelo previsto em seu $\S 1^{\circ}$, que estabelece a época do pagamento, definindo que, "quando o pagamento houver sido estipulado por 
mês, deverá ser efetuado, o mais tardar, até o quinto dia útil do mês subsequente ao vencido".

Assim, a legislação definiu expressamente uma data limite para o empregador cumprir a sua principal obrigação junto aos seus trabalhadores, qual seja, pagar-lhes o salário. A estipulação do pagamento até o quinto dia útil permite ao empregado e ao empregador organizar suas movimentações financeiras, facilitando, assim, o controle contábil da empresa e a administração doméstica dos empregados.

Uma prática constatada nas relações de emprego é o pagamento de um "vale", no valor de 50\% do salário, próximo ao vigésimo dia do mês, e o restante até o quinto dia útil. Diversas Convenções Coletivas já negociaram tal previsão e a jurisprudência já pacificou o assunto quanto à possibilidade da alteração da data do pagamento do salário, por meio da Orientação Jurisprudencial no 159 , da Seção Especializada em Dissídios Individuais do Tribunal Superior do Trabalho, que giza "diante da inexistência de previsão expressa em contrato ou instrumento normativo, a alteração de data de pagamento pelo empregador não viola o art. 468, desde que observado o parágrafo único, do art. 459, ambos da CLT."

Assim, o pagamento do salário é a principal obrigação do empregador, devendo ser efetivado, por determinação legal, até o quinto dia útil de cada mês. O salário é pago em todos os meses em que o contrato de emprego não esteja suspenso, destacando que, nos casos de interrupção, por exemplo, descanso semanal remunerado e férias, o pagamento do salário permanece inalterado, ou seja, o empregado sabe que nos doze meses do ano receberá o seu salário até o quinto dia útil.

\subsection{Décimo terceiro salário}

O décimo terceiro salário, também chamado de gratificação natalina, é um direito trabalhista constitucionalmente garantido. A Constituição Federal de 1988 (BRASIL, 1988) previu expressamente, em seu artigo $7^{\circ}$, inciso VIII, como direito dos trabalhadores urbanos e rurais o décimo terceiro salário, com base na remuneração integral ou no valor da aposentadoria. Como já mencionado acima, o décimo terceiro salário tem como base de cálculo a remuneração do empregado.

Tal instituto foi estabelecido pela Lei 4.090 de 1962, regulamentado pelo Decreto 57.155, de 1965, com acréscimos introduzidos pela Lei 4.749 de 1965.

A figura da gratificação natalina tem origem em práticas concessivas 
unilaterais pelo empregador, tendo, inicialmente, se consolidado por meio de negociação coletiva e, por fim, no ano de 1960, passou a integrar o arcabouço jurídico legal com a promulgação da Lei 4.090.

A Lei 4.090 estabelece em seu artigo $1^{\circ}$ que "no mês de dezembro de cada ano, a todo empregado será paga, pelo empregador, uma gratificação salarial independentemente da remuneração a que fizer jus".

A mesma legislação firmou que tal gratificação corresponderá a 1/12 (um doze avos) da remuneração devida em dezembro, por mês de serviço, do ano correspondente, bem como que a fração igual ou superior a 15 dias de trabalho será havida como mês integral para os efeitos do parágrafo anterior.

Inegável que o décimo terceiro salário é um dos grandes direitos alcançados aos trabalhadores, aumentando consideravelmente $(8,3 \%)$ a renda anual do empregado. Destaca-se que os valores, dispensados no décimo terceiro salário, em regra, retornam imediatamente para a economia, seja no adimplemento de dívidas já consolidadas, seja na aquisição de novos bens de consumo.

Destaca-se que o instituto do décimo terceiro salário também está previsto na legislação de diversos outros países, como, por exemplo, Argentina, Uruguai, México, Portugal, Espanha e Itália. ${ }^{4}$

O Decreto 57.155 de 1965 estabeleceu os critérios de data de pagamento da gratificação natalina, estipulando que a disponibilização dos valores deve ser realizada até o dia 20 de dezembro do ano corrente. Autorizou, também, o empregador fazer um pagamento, de uma só vez, entre fevereiro e novembro, de cinquenta por cento do valor do salário do mês anterior, como adiantamento de tal direito. Por fim, também previu a possibilidade de o pagamento desse adiantamento quando das férias do empregado, desde que este tenha requerido no mês de janeiro do ano correspondente.

Inegável a natureza salarial do instituto, tanto que o Supremo Tribunal Federal já editou súmula (688) declarando a legitimidade da incidência da contribuição previdenciária sob tal parcela. Além disso, a natureza salarial também o faz devido nas resilições contratuais. Quando a rescisão contratual ocorre antes de completar um ano de contrato, o pagamento do décimo terceiro salário é devido de forma proporcional, na fração de um doze avos para cada mês

\footnotetext{
4 DÉCIMO TERCEIRO SALÁRIO. In: WIKIPÉDIA, a enciclopédia livre. Flórida: Wikimedia Foundation, 2019. Disponível em:

$<$ https://pt.wikipedia.org/w/index.php?title=D\%C3\%A9cimo_terceiro_sal\%C3\%A1rio\&oldid=56579744> . Acesso em: 28 out. 2019.
} 
em que o empregado tenha trabalhado mais de 15 dias.

A lei prevê, entretanto, que nos casos de resoluções contratuais, ou seja, rescisões por justa causa do empregado, tal parcela não é devida pelo empregador.

O Tribunal Superior do Trabalho já pacificou o entendimento de que integram a base de cálculo do décimo terceiro salário as verbas recebidas in natura, as gorjetas, adicionais habituais de horas extras, adicionais noturnos, de insalubridade, de periculosidade e de transferência.

O pedido de pagamento integral ou parcial de gratificação natalina consta das inúmeras reclamatórias trabalhistas, diariamente ajuizadas nos Tribunais Regionais do Trabalho, distribuídos no território nacional. Tais ações indicam que, em muitas situações, o empregador não quita a parcela apenas no último ano de contrato, quando do pagamento das verbas rescisórias, mas também nos demais anos de duração do contrato de emprego.

O que se pode constatar, enfim, é que o empregado fica sujeito à vontade do empregador pelo pagamento do décimo terceiro salário, só realmente tendo plena certeza do seu recebimento no dia 20 de dezembro de cada ano, quando do efetivo pagamento da verba. Nos casos de não recebimento, o empregado pode se ver compelido a só ter acesso à parcela se ajuizar uma reclamatória trabalhista e obter um provimento judicial favorável determinando o seu pagamento e o executando.

\subsection{Férias e adicional de um terço:}

A definição de férias para Maurício Godinho Delgado (2002, P. 952):

lapso temporal remunerado, de frequência anual, constituído de diversos dias sequenciais, em que o empregado pode sustar a prestação de serviços e sua disponibilidade perante o empregador, com o objetivo de recuperação e implementação de suas energias e de sua inserção familiar, comunitária e política.

As férias são um típico instituto de interrupção do contrato de trabalho, onde a obrigação principal do empregado, de disponibilizar sua força e seu tempo de trabalho, encontra-se paralisado por tempo determinado, porém, todas as demais obrigações das partes permanecem intocáveis, inclusive o pagamento de salário. 
As férias não têm como interessado exclusivo o próprio trabalhador, tal instituto também tem fundamento em considerações e metas relacionadas à política de saúde pública, bem-estar coletivo e respeito à própria construção da cidadania (DELGADO, 2002, p. 952).

Tal direito tem previsão expressa na Constituição Federal de 1988 (BRASIL, 1988), conforme artigo $7^{\circ}$, inciso XVII, bem como na CLT (Decreto Lei 5.452, de $1^{\circ}$ de maio de 1943), em seus artigos 129 ao 153, regulamentando-o.

As férias devem ser gozadas nos doze meses seguintes, ao término do período aquisitivo, ou seja, o empregado trabalha todo o primeiro ano e no segundo ano de contrato deve gozar as férias referentes ao ano anterior e assim sucessivamente. O período de doze meses trabalhado pelo empregado é chamado de período aquisitivo e os dozes meses subsequentes, no qual o empregador deve conceder as férias, é chamado de período concessivo.

A Constituição Federal de 1988 garante, ao empregado, o pagamento do salário normal acrescido de um terço, ou seja, um terço a mais do que o salário mensal normal. Tal instituto tem o intuito de possibilitar que o empregado, ao sair de férias, tenha algum valor que lhe possibilite usufruir alguma forma de lazer.

O artigo 145, da CLT, determina que o pagamento da remuneração das férias será efetuado até dois dias antes do início do respectivo período. O período de concessão das férias será aquele que melhor consulte os interesses do empregador, conforme previsto no artigo 136, da CLT. Esses dispositivos legais estipulam precisamente o dia do pagamento do adicional de um terço do salário referente ao período das férias, bem como a fruição de acordo com os interesses do empregador.

Assim como, no caso do pagamento do décimo terceiro salário, o empregado fica na expectativa do pagamento das férias, da efetiva fruição do descanso e, ainda, do recebimento do adicional de um terço.

\section{Salário diferido ou empréstimo compulsório}

As figuras, que integram o complexo remuneratório do empregado, têm previsão legal estipuladas à época do seu pagamento. O salário é pago, em regra, mensalmente, o décimo terceiro salário é pago anualmente, até dia 20 de dezembro, e o adicional de um terço das férias deve ser pago dois dias antes do início da fruição. 
As definições com projeção de época para pagamento aproximam tais institutos do conceito de salário diferido. Amauri Mascaro Nascimento (2001, p. 374) explica que o salário diferido é o salário cujo direito é adquirido no presente, mas a utilização é projetada para o futuro. O mesmo autor (NASCIMENTO, 2014, p. 374) exemplifica com o Fundo de Garantia por Tempo de Serviço, afirmando que é uma das figuras de salário diferido, ou seja, é um valor que pertence ao empregado, mas ainda não disponibilizado, pois a lei traz critérios específicos e objetivos para que o empregado tenha acesso, ou seja, os depósitos podem ter sido efetuados, porém, não liberados.

Para Arnaldo Süssekind (2002, p. 644), salário diferido se conceitua como aquele que é adquirido no presente, porém, será utilizado em momento posterior, ou seja, não é pago imediatamente ao empregado, mas em momento futuro.

É de conhecimento público que os empresários, ao analisar a contratação de um empregado, levam em consideração o custo anual que tal contratação agregará ao seu orçamento e, nesse custo, estão inseridos os valores do décimo terceiro salário e do adicional de férias, além da ausência de prestação de serviços no período de fruição do respectivo descanso.

Algumas Convenções Coletivas, bem como alguns empregadores tentaram negociar o pagamento de tais verbas mensalmente, ou seja, totalizar o valor do décimo terceiro salário e do adicional de férias, dividir por doze e pagar mensalmente junto com o salário.

Destaca-se que, nesses casos, não há que se falar em salário complessivo, instituto conceituado pela súmula 91 do Colendo Tribunal Superior do Trabalho, que define ser nula cláusula contratual que fixa determinada importância ou percentagem para atender, englobadamente, vários direitos legais ou contratuais do trabalhador. Ou seja, o empregador não irá somar tais parcelas e nominálas como salário ou remuneração no contracheque do empregado, pois o que se pretende é o pagamento de tais verbas, com suas específicas denominações e identificações no contracheque, de forma mensal e direta.

Do contrário, o empregado, até a efetiva percepção, fica, apenas, com a expectativa do recebimento de um direito já constituído, mesmo porque a partir do décimo quinto dia do mês, já faz jus ao décimo terceiro salário e às férias proporcionais.

Entende-se, então, que a manutenção desses valores em poder do empregador, que também ostenta o poder de decidir se irá pagar ou não quando 
da chegada do período legal estipulado, nada mais é do que se não um empréstimo compulsório que o empregado faz ao seu empregador, empréstimo esse que não tem incidência de juros nem de correção monetária.

Explica-se. A lei estabelece que a partir do décimo quinto dia do mês de trabalho nasce ao empregado o direito de percepção do décimo terceiro salário, bem como do adicional de férias, tanto que nos casos de rescisão contratual, antes do término do primeiro ano de contrato o empregado recebe, dentre as verbas rescisórias devidas, o décimo terceiro salário proporcional e as férias proporcionais.

Então, considerando-se que o direito nasce nesse momento, o direito de receber os valores pecuniários decorrentes desse direito também nasce e seu consequente pagamento deveria ocorrer no mês imediatamente seguinte, porém, a lei expressamente postergou esse pagamento, caracterizando o salário diferido.

Cumpre destacar que, além de deixar esses valores na posse do empregador, postergando o seu recebimento no tempo, o empregado ainda assume o risco de, quando implementado o termo para o pagamento, o empregador simplesmente não o adimplir. Pondera-se que o não pagamento pelo empregador pode ser até mesmo justificado por eventual crise financeira, de modo que, quanto mais se posterga o prazo de pagamento, maior é o risco assumido.

Ocorrendo inadimplemento, só resta ao empregado a esperança de o empregador espontaneamente lhe pagar tal obrigação no decorrer do contrato de trabalho ou quando do pagamento das verbas rescisórias ou, não sendo o caso, por fim, vir a receber por meio de reclamatória trabalhista.

A propósito, não se vislumbra, salvo raras exceções, reclamatória trabalhista com contrato de emprego ativo, assim o empregado pode vir a ter acesso a tais verbas, unicamente, quando do término do contrato e após o ajuizamento, processamento, julgamento e execução de uma ação, que lhe garanta o direito de percepção do respectivo valor, além de poder ter alguma parcela coberta pelo manto da prescrição.

Ademais, não se pode perder de vista que o empregador poderá negociar um acordo judicial com parcelamento de tais verbas, quiçá em valor inferior ao realmente devido, sem esquecer que o próprio Código de Processo Civil autoriza o parcelamento da execução nos moldes do artigo 916 em até sete parcelas. 


\section{Do parcelamento}

Diante do exposto, discute-se a possibilidade de parcelamento do pagamento dos valores devidos a título de décimo terceiro salário e adicional de um terço de férias. Os dois institutos possuem inegável natureza salarial, com previsão legal expressa quanto à época de pagamento, além do que são direitos alcançados, proporcionalmente, mês a mês.

Sendo assim, por que não possibilitar a percepção de tais valores de forma contínua e perene em todos os meses no decorrer do ano corrente?

Tal questionamento se mostra tão presente que, em 2019, foi apresentado um projeto de lei permitindo o parcelamento do décimo terceiro salário. O projeto de lei 5.337/2019 prevê a inserção do $\S 4^{\circ}$, no artigo 1, da Lei 4.090 de 1960, facultando ao empregador e ao empregado, mediante acordo formal, parcelar o décimo terceiro salário em até 12 meses. Tal projeto, já estipula, inclusive, que os descontos previdenciários e fiscais deverão ser recolhidos mensalmente. Atualmente, o projeto está em trâmite na Câmara dos Deputados, tendo sido determinado pela Mesa Diretora que se crie uma Comissão Especial, para analisar a matéria, em novembro de 2019.

A justificativa apresentada no projeto de lei é de clareza ímpar, o pagamento do décimo terceiro salário em duas parcelas, por muitas vezes, onera o empregador de forma demasiada, levando, em grande parte dos casos, ao inadimplemento.

Afirma que o número de vendas não aumenta proporcionalmente, nesse período do ano, e acaba causando um desequilíbrio nas contas da empresa. Ademais, o aumento de vendas se restringe ao comércio e a uma parte específica da indústria, de modo que essa injeção financeira não é uma realidade para os demais trabalhadores.

Nesse contexto, a possibilidade de parcelamento é um anseio tanto dos empregados quanto dos empregadores, porém, até este momento, a lei só prevê a possibilidade do pagamento em duas parcelas.

Quanto ao adicional do terço das férias, o pagamento é previsto única e exclusivamente até dois dias antes do início do gozo. Também, neste caso, deveria ser possibilitado o parcelamento de tal verba no decorrer do ano: de um lado, proporcionando antecipadamente o acesso a tais valores pelo empregado; e, de outro, contribuindo como facilitador de gastos na contabilidade do empregador.

$\mathrm{O}$ acesso antecipado de tais parcelas autoriza, ao seu credor, definir o 
destino conforme bem entender, podendo quitar dívidas, reduzindo taxa de juros, ou até mesmo investir, recebendo juros e correção monetária. É de simples constatação que a manutenção desses valores, em poder do empregador, só traz benefícios ao devedor, ou seja, ele fica em poder dos valores, investe conforme seu melhor entendimento e ainda decide se irá (ou não) pagar corretamente no momento determinado pela lei, ou seja, é ilógico não autorizar a antecipação de tal pagamento no decorrer dos meses.

Destaca-se que a Lei 13.467 de 2017 - Reforma Trabalhista, inseriu algumas alterações na legislação laboral, inclusive previu expressamente a prevalência do negociado sobre o legislado.

O artigo 611-A, com redação dada pela Lei 13.467, estabelece que a convenção coletiva e o acordo coletivo de trabalho têm prevalência sobre a lei e apresenta um rol exemplificativo de direitos, que podem ser alvo da negociação coletiva, com prevalência sobre o legislado.

Já o seu artigo 611-B reconhece a ilicitude de convenção coletiva ou de acordo coletivo de trabalho, exclusivamente quando suprimir ou a reduzir os direitos ali listados, estando, dentre eles, o valor nominal do décimo terceiro salário e o gozo de férias anuais remuneradas com, pelo menos, um terço a mais do que o salário normal.

O parcelamento de tais verbas não caracteriza, de forma alguma, supressão ou redução do décimo terceiro salário nem do adicional do terço de férias, pelo contrário, possibilita a transferência de renda de forma mais imediata e constante ao empregado, aumentando o seu rendimento mensal, estimulando o consumo e a organização financeira familiar.

Tal possibilidade, conforme previsto no projeto de lei 5.337/2019, em eventual negociação coletiva que possa a vir surgir nas entidades sindicais, pode autorizar ao empregado e ao empregador negociarem a possibilidade de parcelamento.

A situação transfere aos protagonistas da relação jurídica empregatícia a possibilidade de negociarem entre si, conforme os seus interesses, a disposição dos valores devidos. O empregado tem que ter autoridade sobre os seus direitos, podendo negociar a forma de seu recebimento. $\mathrm{O}$ artigo $7^{\circ}$ da $\mathrm{CF} / 88$ (BRASIL, 1988) deixa claro que o rol de direitos ali listados se acrescem daqueles que visem à melhoria de sua condição social; então, se entender que a percepção de tais verbas, proporcionalmente por meio de pagamento mensal, acarreta melhoria em sua condição social e, não sendo alvo específico de ilicitude ou de proibição 
de negociação, cabe avalizar e autorizar tais situações.

Não se pode esquecer que, quem tem que deter o poder de autorizar o parcelamento ou requisitar que o pagamento seja assim realizado, é o seu credor, ou seja, o empregado. Sendo assim, a lei ou as convenções coletivas podem estipular que o empregado possa requerer o pagamento parcelado do décimo terceiro salário e do seu terço adicional de férias, nos moldes do artigo 143, da CLT, que, ademais, faculta ao empregado converter $1 / 3$ do período de férias em abono pecuniário, sendo um direito potestativo do empregado, cabendo apenas a comunicação ao empregador.

Por fim, o argumento de que tal pagamento parcelado dificultaria o recebimento dos valores adiantados pelo empregador nos casos de despedida por justa causa, situação em que não são devidos o pagamento do décimo terceiro e, das férias proporcionais, não pode ser impedimento. Primeiro, porque os casos de resolução contratual, por culpa do empregado, acontecem em número consideravelmente reduzido e, segundo, porque é possível que a negociação coletiva preveja o desconto de tais parcelas das verbas rescisórias, respeitado o limite de uma remuneração. Aliás, inclusive, a MP 927/2020 que trata da concessão de férias no período de pandemia da COVID-19, previu a possibilidade de desconto do pagamento do adicional de férias nos casos de rescisão (Art. 10).

Não se pode esquecer de destacar que o pagamento parcelado facilitará, por fim, a quitação das verbas rescisórias nos casos de rescisão unilateral pelo empregador, pois o empregado já terá recebido parte de tais valores, devendo o empregador pagar apenas a proporção do mês trabalhado e de eventual avisoprévio proporcional.

\section{Considerações finais}

Diante de todo o exposto, conclui-se que a ausência de autorização legal para o pagamento parcelado dos valores de décimo terceiro salário e do adicional do terço de férias, no decorrer do ano corrente, impedia que empregados e empregadores negociassem tal situação.

Os benefícios do recebimento parcelado de tais verbas é patente, facilitando a inclusão de tais valores na contabilidade do empregador e permitindo ao empregado destiná-los, conforme suas necessidades.

A Reforma Trabalhista estipulou expressamente a prevalência do negociado sobre o legislado e abriu portas para que empregados e empregadores 
negociem tal parcelamento. Cabe, portanto, aos sindicatos se atentarem para essa possibilidade e visualizarem que negociações desse jaez contribuirão não só para a melhoria da condição social do trabalhador, como também, no contexto geral, para o fortalecimento e crescimento da classe econômica, com a consequente manutenção e até ampliação do quadro de empregos, aqui, diga-se, mais uma vez, em inegável retorno benéfico à classe operária.

A existência de um projeto de lei, prevendo o parcelamento do décimo terceiro, deixa claro que a sociedade também tem interesse nessa opção.

Conclui-se que, a partir da "autorização" legislativa os protagonistas da relação de emprego, em conjunto com as respectivas entidades sindicais representativas, poderão passar a negociar tal possibilidade. Releva destacar que, ao negociar, sejam abordados todos os pontos que o parcelamento pode vir a afetar, a exemplo dos recolhimentos previdenciários e fiscais e eventuais descontos dos adiantamentos, em caso de rescisão por justa causa.

Destaca-se, por fim, o entendimento de que a possibilidade de parcelamento dessas verbas deva ser uma opção do empregado, de forma que a lei e as negociações coletivas autorizem o empregado simplesmente a optar, sem prejuízo da previsão legal atual de recebimento, que é até o dia 20 de dezembro quanto ao décimo terceiro salário e até dois dias antes no caso do adicional de férias.

\section{Referências bibliográficas}

BRASIL. Constituição Federal (1988). Disponível em: http://www.planalto.gov. br/ccivil_03/constituicao/constituicaocompilado.htm . Acesso em: 01 fev. 2020.

BRASIL. Decreto-Lei $n^{\circ} .5,452$, de $1^{\circ}$ de maio de 1943. Aprova a Consolidação das Leis do Trabalho. Disponível em: http://www.planalto.gov.br/ccivil_03/ decreto-lei/Del5452.htm >. Acesso em: 01 fev. 2020.

BRASIL. Lei $n^{\circ}$.4.090, DE 13 DE JULHO DE 1962. Institui a Gratificação de Natal para os trabalhadores. Disponível em: < http://www. http://www.planalto. gov.br/ccivil_03/LEIS/L4090.htm > . Acesso em: 01 fev. 2020. 
BRASIL. Lei $n^{\circ}$ 4.749, DE 12 DE AGOSTO DE 1965. Dispõe sobre o Pagamento da Gratificação Prevista na Lei n ${ }^{\circ} 4.090$, de 13 de julho de 1962. Disponível em: < http://www.planalto.gov.br/ccivil_03/leis/L4749.htm>. Acesso em: $01 \mathrm{fev}$. 2020 .

BRASIL. Lei $n^{\circ}$ 13.105, DE 16 DE MARÇO DE 2015.

Código de Processo Civil. Disponível em: < http://www.planalto.gov.br/ ccivil_03/_ato2015-2018/2015/lei/113105.htm > . Acesso em: 01 fev. 2020.

BRASIL. Lei $n^{\circ} 13.467$, DE 13 DE JULHO DE 2017.

Disponível em: < http://www.planalto.gov.br/ccivil_03/_ato2015-2018/2017/lei/ 113467.htm >. Acesso em: 01 fev. 2020.

BRASIL. Medida Provisória 927, DE 22 DE MARÇO DE 2020.

Disponível em: < http://www.planalto.gov.br/ccivil_03/_ato2019-2022/2020/ Mpv/mpv927.htm > . Acesso em: 05 abr. 2020.

BRASIL. Projeto de Lei $n^{\circ} 5.337$, DE 2019. Altera a LEI No 4.090, DE 13 DE JULHO DE 1962 para permitir o parcelamento do décimo terceiro salário.

BRASIL. Tribunal Superior do Trabalho. Súmula $n^{0}$ 91. Súmulas, Orientações Jurisprudenciais, Precedentes Normativos - Brasília: CSG/SEG/TJDFT, 2016. Disponível em: < http://www.tst.jus.br/documents/10157/63003/Livro-Internet. pdf $>$. Acesso em: 23 mar. 2020.

CONSELHO NACIONAL DE JUSTIÇA. Justiça em números 2019. Disponível em: < https://www.cnj.jus.br/pesquisas-judiciarias/justica-em-numeros/ >. Acesso em: 04 fev. 2020.

NASCIMENTO, Amauri Mascaro; Nascimento, Sonia Mascaro. Iniciação ao Direito do Trabalho. ed. 27. São Paulo: LTr, 2002.

SÜSSEKIND, Arnaldo; Maranhão, Délio; Vianna; Segadas; Teixeira, Lima. Instituições de Direito do Trabalho. ed, 19. São Paulo: LTr, 2002.

DELGADO, Mauricio Godinho. Curso de Direito do Trabalho. São Paulo: LTr, 2002. 
BARROS, Alice Monteiro de. Curso de Direito do Trabalho. 5. ed. Ver. e ampl. - São Paulo: LTr, 2009.

SILVA, Homero Batista Mateus da. Curso de Direito do Trabalho aplicado, vol. 5: Livro da remuneração. Rio de Janeiro: Elsevier, 2009.

MOURA, Marcelo. Consolidação das Leis do Trabalho para Concursos. Salvador: Editora Podium, 2011. 